\title{
Mediterranean food pattern and the primary prevention of chronic disease: recent developments
}

\author{
Miguel Angel Martinez-Gonzalez, Maira Bes-Rastrollo, Lluis Serra-Majem, Denis Lairon, Ramón Estruch, \\ and Antonia Trichopoulou
}

\begin{abstract}
Recent evidence supports the cardioprotective role of a Mediterranean food pattern. The major findings of the Greek and EPIC-Elderly cohort, the SUN study, the Medi-RIVAGE and the PREDIMED trials are reviewed. Definitive answers will come from ongoing primary prevention trials that assess clinical events as outcomes.
\end{abstract}

๑) 2009 International Life Sciences Institute

\section{INTRODUCTION}

Worldwide, the leading cause of mortality and disabilityadjusted life-years lost is cardiovascular disease (CVD). ${ }^{1}$ A clustering of CVD risk factors (obesity, type 2 diabetes, hyperlipidemia, and hypertension) has been reported repeatedly and has been related to the metabolic syndrome. ${ }^{2,3,4}$ The dramatic rise in the prevalence of these conditions threatens to reverse the reductions in CVD risk observed in most Western countries and also to cause a pandemic expansion of CVD in many developing countries. These major CVD risk factors, especially obesity and hypertension, are amenable to preventive interventions through population changes in dietary habits. The Mediterranean food pattern (MFP) has attracted considerable interest because of its potential advantages in the prevention of CVD. ${ }^{5}$

The term MFP was defined at the International Conference on the Diets of the Mediterranean in $1993^{6}$ as the dietary pattern found in the olive-growing areas of the Mediterranean region during the early 1960s, as characterized by the following: high olive oil consumption; high consumption of legumes; high consumption of unrefined cereals; high consumption of fruits; high consumption of vegetables; moderate consumption of dairy products, mostly as cheese and yogurts; moderate-to-high consumption of fish; low consumption of meat and meat products; and moderate wine consumption.

The yearly number of publications on this subject has increased from less than 10 in 1985 to more than 100 in 2005, as the scientific community has recognized the need for further clinical and longitudinal epidemiological studies to achieve sound, evidence-based recommendations. This is important since most of the scientific articles published are observational epidemiological studies (primarily ecological, cross-sectional, or case-control studies), and almost all the reviews published are nonsystematic and reflect merely an opinion or a collection of articles rather than an objective analysis of robust evidence. ${ }^{7}$ This article presents some of the most recent developments in assessing the value of an MFP against the occurrence of chronic diseases, including results from ongoing intervention studies such as the Medi-RIVAGE study in France, the PREDIMED study in Spain, and prospective cohorts such as the EPIC study and the SUN study that have been presented at the I World Conference of Public Health Nutrition in Barcelona.

\begin{abstract}
Affiliations: MA Martinez-Gonzalez and M Bes-Rastrollo are with the Department of Preventive Medicine and Public Health, Clinica Universitaria, University of Navarra, Pamplona, Spain. L Serra-Majem is with the Mediterranean Diet Foundation, University of Barcelona Science Park, and the Department of Clinical Science, University of Las Palmas de Gran Canaria, Las Palmas de Gran Canaria, Spain. $D$ Lairon is with the Nutrition Humaine et Lipides, INSERM, INRA, and the Faculté de Médecine, Marseille, France. $R$ Estruch is with the Department of Internal Medicine, Hospital Clinic, Barcelona, Spain. A Trichopoulou is with the WHO Collaborating Centre for Nutrition, and the Medical School, University of Athens, Athens, Greece.
\end{abstract}

Correspondence: MA Martinez-Gonzalez, Departamento de Medicina Preventiva y Salud Pública, Clinica Universitaria, Facultad de Medicina, Irunlarrea 1, 31080 Pamplona, Spain. E-mail: mamartinez@unav.es, Phone: +34-94-842-5600 ext. 6463, Fax: +34-94-842-5649.

Key words: blood pressure, dietary patterns, follow-up studies, intervention studies, monounsaturated fat 


\section{METHODS USED IN MAJOR STUDIES INVESTIGATING THE MEDITERRANEAN FOOD PATTERN}

\section{Mediterranean diet and survival: the EPIC study in Greece and in an elderly European population}

The definition of the MFP was operationalized by developing an a priori 10-point score. A value of 0 or 1 was assigned to each of nine indicated components, with the sex-specific medians used as the cutoff points. For beneficial components (vegetables, legumes, fruits and nuts, cereal, and fish), persons whose consumption was below the median were assigned a value of 0 , and all others were assigned a value of 1 . For components presumed to be detrimental (meat and dairy products), persons whose consumption was below the median were assigned a value of 1 , and all others were assigned a value of 0 . A value of 1 was given to men consuming $10-<50 \mathrm{~g}$ of alcohol per day and to women consuming 5-25 g. For lipid intake, the ratio of monounsaturated fatty acids [MUFAs] to saturated fatty acids [SFA] was calculated. Those above the sex-specific median in the MUFA/SFA ratio were given 1 point. Thus, the total Mediterraneandiet score ranged from 0 (minimal adherence to the traditional Mediterranean diet) to 9 (maximal adherence) ${ }^{8,9}$ To assess the relationship between MFP and overall mortality in a large sample of the general Greek population and in elderly participants of the EPIC study, Cox's multivariate regression models were used, adjusting for potential confounders.

\section{Mediterranean diet in the primary prevention of nutrition-related chronic disease: the SUN study}

The SUN study is a dynamic cohort of Spanish university graduates. ${ }^{10,11}$ It began in 1999 and, as of September 2007, included more than 17,000 participants. Selfreported data on obesity, hypertension, and physical activity have been validated. ${ }^{12,13,14}$ A semiquantitative food frequency questionnaire previously validated in Spain is included. ${ }^{15}$

Cohort members who answered the baseline questionnaire before 11 November 2003 and who thus had the chance to complete at least the first 2-year follow-up questionnaire were included. In the analyses that used hypertension as the outcome, prevalent cases of hypertension and prevalent cases of cardiovascular disease, diabetes, or cancer were excluded. Participants with extreme caloric intake or missing information in covariates were excluded. Among the remaining participants, $87-91 \%$ (depending on the specific analysis) answered at least one follow-up questionnaire between 2002 and 2006.

Nonconditional logistic regression modeling or Cox's proportional hazard regression was used to adjust for potential confounders, with quintiles of energyadjusted olive oil consumption and vegetable protein intake considered as the exposure and incident cases of hypertension as the outcome.

The association between quintiles of baseline olive oil consumption and the subsequent change in body weight was estimated using least-squares regression models. The lowest quintile of total baseline olive oil consumption was considered as the reference category of exposure, and weight change during follow-up as the outcome.

Nonconditional logistic regression models were fitted to appraise the relationship between categories of nut consumption and the risk of weight gain $(\geq 5 \mathrm{~kg}$ ) or the risk of becoming overweight/obese (body mass index $[\mathrm{BMI}] \geq 25 \mathrm{~kg} / \mathrm{m}^{2}$ ).

\section{Medi-RIVAGE intervention study in subjects at high cardiovascular risk}

The Medi-RIVAGE study is an intervention study with a Mediterranean diet-based nutritional approach that included 212 volunteers from La Timone University Hospital (Marseille, France) who were at high cardiovascular risk. A Mediterranean-type diet (Med group) was compared to a low-fat diet (low-fat group) for risk factors of cardiovascular disease. The assessment included 169 patients who met at least one of the following eligibility criteria: fasting plasma cholesterol concentration of 6.5-7.7 mmol/L; triacylglycerol concentration of 2.1$4.6 \mathrm{mmol} / \mathrm{L}$; glycemia (glucose concentration of $6.1-$ $6.9 \mathrm{mmol} / \mathrm{l})$; systolic and diastolic pressure between 140-180 and 90-105 $\mathrm{mm} \mathrm{Hg}$, respectively; BMI (in $\left.\mathrm{kg} / \mathrm{m}^{2}\right)>27$; smoking; sedentary lifestyle; or family history of CVD. ${ }^{16}$ After 3 months of dietary intervention, changes in plasma concentration of glucose, insulin, total cholesterol, low-density lipoprotein [LDL] cholesterol, highdensity lipoprotein [HDL] cholesterol, triacylglycerols, fatty acids, carotenoids, vitamin $B_{12}$, folates, apolipoprotein (apo) E, apo A-I, apo B, and apo C-III, and insulin resistance by homeostasis model assessment (HOMA) were evaluated using a repeated measures two-factor analysis of covariance.

\section{Effects of a Mediterranean-type diet on cardiovascular risk factors: the PREDIMED randomized trial}

The PREDIMED (Prevencion con Dieta Mediterránea, meaning Prevention with Mediterranean Diet) study is a large-scale, ongoing, multicenter, randomized, primary prevention trial in a high-risk population to assess the effects of three healthy diets (low-fat diet, Mediterranean diet rich in olive oil, and Mediterranean diet rich in tree nuts) on cardiovascular outcomes (http://www.unav.es/ 
Table 1 Adjusted hazard ratios (HRs) for total mortality associated with a two-point increment in the Mediterranean-diet score in the EPIC study.

\begin{tabular}{|c|c|c|}
\hline Study population & $\begin{array}{l}\text { No. of deaths/no. } \\
\text { of participants }\end{array}$ & $\mathrm{HR}^{*}(95 \% \mathrm{Cl})$ \\
\hline Greek EPIC & $275 / 22,043$ & $0.75(0.65-0.87)$ \\
\hline $\begin{array}{l}\text { European EPIC-elderly } \\
\quad(\geq 60 \text { years })\end{array}$ & $4,047 / 74,607$ & $.88-0.97)$ \\
\hline \multicolumn{3}{|c|}{$\begin{array}{l}\text { * Greek EPIC data adjusted for age, gender, waist-to-hip ratio, energy-expenditure score, } \\
\text { years of education, smoking status, body mass index, consumption of potatoes, } \\
\text { consumption of eggs, and total energy intake. European EPIC-Elderly data adjusted for } \\
\text { age, gender, diabetes mellitus at baseline, waist-to-hip ratio, body mass index, } \\
\text { educational achievement, smoking status, physical activity at work, physical activity at } \\
\text { leisure, consumption of potatoes, consumption of eggs, consumption of sugar and } \\
\text { confectionery, and total energy intake. }\end{array}$} \\
\hline
\end{tabular}

preventiva/predimed). ${ }^{17}$ In the pilot study, 772 asymptomatic persons aged 55 to 80 years with at least one of the two following eligibility criteria were included: 1) type 2 diabetes and 2) $\geq 3$ major cardiovascular risk factors (current smoker, hypertension, LDL cholesterol $\geq 160 \mathrm{mg} / \mathrm{dL}, \mathrm{HDL}$ cholesterol $\leq 40 \mathrm{mg} / \mathrm{dL}, \mathrm{BMI} \geq 25 \mathrm{~kg} /$ $\mathrm{m}^{2}$, or a family history of premature cardiovascular disease). Personalized dietary advice, which included recommendations on the desired frequency of intake of specific foods as well as advice to reduce the intake of all types of fat, was given to each participant during a 30-minute session, along with a leaflet that included American Heart Association recommendations. Those assigned to the two Mediterranean diet groups had a more intense behavioral and educational intervention. Depending on the group, participants allocated to the two Mediterranean-type diets were given either complimentary virgin olive oil or walnuts ( $15 \mathrm{~g} /$ day $)$, hazelnuts $(7.5 \mathrm{~g} /$ day $)$, and almonds (7.5 g/day). A 1-hour group session at baseline was conducted specifically for each Mediterranean group, during which participants were provided with written materials. Body weight, blood pressure, lipid profile, glucose levels, and inflammatory molecules were evaluated at 3 months of follow-up.

\section{RESULTS OF MAJOR STUDIES INVESTIGATING THE MEDITERRANEAN FOOD PATTERN}

\section{Mediterranean diet and survival: the EPIC study in Greece and in an elderly European population}

A higher degree of adherence to the Mediterranean diet was associated with a reduction in total mortality (Table 1). ${ }^{8}$ A significant inverse association was apparent for both total death and coronary heart disease mortality or cancer mortality. Associations between individual food groups contributing to the Mediterranean-diet score and total or cause-specific mortality were generally much weaker. Similar results were found for a modified Mediterranean-diet score. ${ }^{9}$

\section{Mediterranean diet in the primary prevention of nutrition-related chronic disease: the SUN study}

Olive oil consumption was not associated with weight gain $^{18}$ but was inversely associated with the incidence of hypertension (Table 2). ${ }^{19}$ Intake of vegetable protein was inversely associated with the risk of hypertension (Table 2) ${ }^{20}$ Adherence to the Mediterranean diet was not related to the incidence of hypertension, but a marginally significant inverse association with weight gain was found. ${ }^{21}$ The consumption of tree nuts was inversely associated with weight gain. ${ }^{22}$

\section{Medi-RIVAGE intervention study in subjects at high cardiovascular risk}

Although the dietary goals were only partially attained, significant changes in dietary habits were observed in both groups (low-fat diet and Mediterranean-type diet). After 3 months of follow-up, participants assigned to a Mediterranean-type diet experienced significantly higher improvements in the majority of the cardiovascular risk factors evaluated compared with those assigned to a lowfat diet (Table 3). ${ }^{23}$

\section{Effects of a Mediterranean-type diet on cardiovascular risk factors: the PREDIMED trial}

A Mediterranean diet supplemented with virgin olive oil or a mixture of nuts resulted in lower blood pressure, improved lipid profiles, decreased insulin resistance, and reduced concentrations of inflammatory molecules after 3 months of follow-up compared with a low-fat diet (Table 4$).{ }^{17}$ 
Table 2 Relative risk (odds ratios or hazard ratios [95\% Cl]) of developing hypertension according to baseline consumption of olive oil or intake of vegetable protein.

\begin{tabular}{|c|c|c|c|c|c|c|}
\hline \multirow[t]{2}{*}{ Consumption pattern } & \multicolumn{5}{|l|}{ Quintile } & \multirow[t]{2}{*}{$P$ for trend } \\
\hline & $\overline{1}$ & 2 & 3 & 4 & 5 & \\
\hline \multicolumn{7}{|l|}{ Olive oil } \\
\hline \multicolumn{7}{|l|}{ Men } \\
\hline No. & 437 & 438 & 438 & 438 & 438 & \\
\hline Multivariate* OR & 1 (ref.) & $0.55(0.28-1.10)$ & $0.75(0.39-1.43)$ & $0.32(0.15-0.70)$ & $0.46(0.23-0.94)$ & 0.02 \\
\hline \multicolumn{7}{|l|}{ Women } \\
\hline No. & 676 & 677 & 677 & 677 & 677 & \\
\hline Multivariate* $O R$ & 1 (ref.) & $0.74(0.27-2.02)$ & $0.97(0.38-2.45)$ & $1.14(0.47-2.78)$ & $0.97(0.40-2.36)$ & 0.74 \\
\hline Vegetable protein & 1 & 2 & 3 & 4 & 5 & $P$ for trend \\
\hline Person-years & 2,722 & 2,727 & 2,722 & 2,709 & 2,646 & \\
\hline${\text { Multivariate }{ }^{\dagger} \mathrm{HR}}$ & 1 (ref.) & $0.5(0.3-0.9)$ & $0.8(0.5-1.4)$ & $0.5(0.3-1.0)$ & $0.5(0.2-0.9)$ & 0.06 \\
\hline
\end{tabular}

\section{CONCLUSION}

The results on mortality obtained from the different databases of the EPIC study were compatible with the reported survival advantage of adult Mediterranean populations when compared with North American and northern European populations. The results suggest the existence of biologic interactions between different components of the Mediterranean diet rather than an effect of only one food group. There is no rationale to maintain the fear that Mediterranean food items rich in fats of vegetable origin (olive oil or tree nuts) may cause weight gain or be responsible for an increased risk of obesity, provided that the energy intake does not exceed energy expenditure. Moreover, the marginal inverse association between adherence to an MFP and weight gain suggests that this association may be apparent with a larger sample.

Although dietary goals were only partially reached, the results from the Medi-RIVAGE study suggest a higher protective effect against cardiovascular risk factors with a Mediterranean-type diet compared to a low-fat diet, with the advantage of greater compliance among those who followed a Mediterranean diet.

Plausible mechanisms for the cardioprotection afforded by an MFP include the improvement of lipid profiles and the substantial reductions in blood pressure, insulin resistance, and levels of systemic markers of inflammation. These results represent only the pilot phase of the PREDIMED trial, which is scheduled to recruit several thousand participants and whose final results, including clinical events, are expected in 2010. A longer follow-up period will eventually provide stronger evidence to evaluate the effect of an MFP supplemented with olive oil or mixed tree nuts on clinical outcomes. ${ }^{17}$ Taken together, these results increase the scientific evidence to support the recommendation of promoting adherence to a MFP in the primary prevention of chronic disease, as presented here, as well as in the secondary prevention of cardiovascular disease, as shown by other studies.

Table 3 Mean relative changes in cardiovascular disease (CVD) risk factors in the Medi-RIVAGE study by treatment group at $\mathbf{3}$ months of follow-up.

\begin{tabular}{lccl}
\hline CVD risk factor & $\begin{array}{l}\text { Mediterranean group } \\
(n=88)\end{array}$ & Low-fat group $(n=81)$ & $P$ value \\
\hline Body mass index & $-5.2 \%$ & $-4.2 \%$ & $<0.05$ \\
Total cholesterol & $-7.4 \%$ & $-4.4 \%$ & $<0.05$ \\
LDL cholesterol & $-9.9 \%$ & $-5.4 \%$ & $<0.05$ \\
HDL cholesterol & $+1.5 \%$ & $+0.03 \%$ & $\mathrm{~ns}$ \\
Triglycerides & $-13.0 \%$ & $-7.9 \%$ & $<0.05$ \\
Glucose & $-3.0 \%$ & $-3.5 \%$ & $<0.05$ \\
Insulin & $-21.3 \%$ & $-17.5 \%$ & $<0.05$ \\
\hline
\end{tabular}

Abbreviations: HDL, high-density lipoprotein; LDL, low-density lipoprotein; ns, nonsignificant differences $(P>0.05)$. 


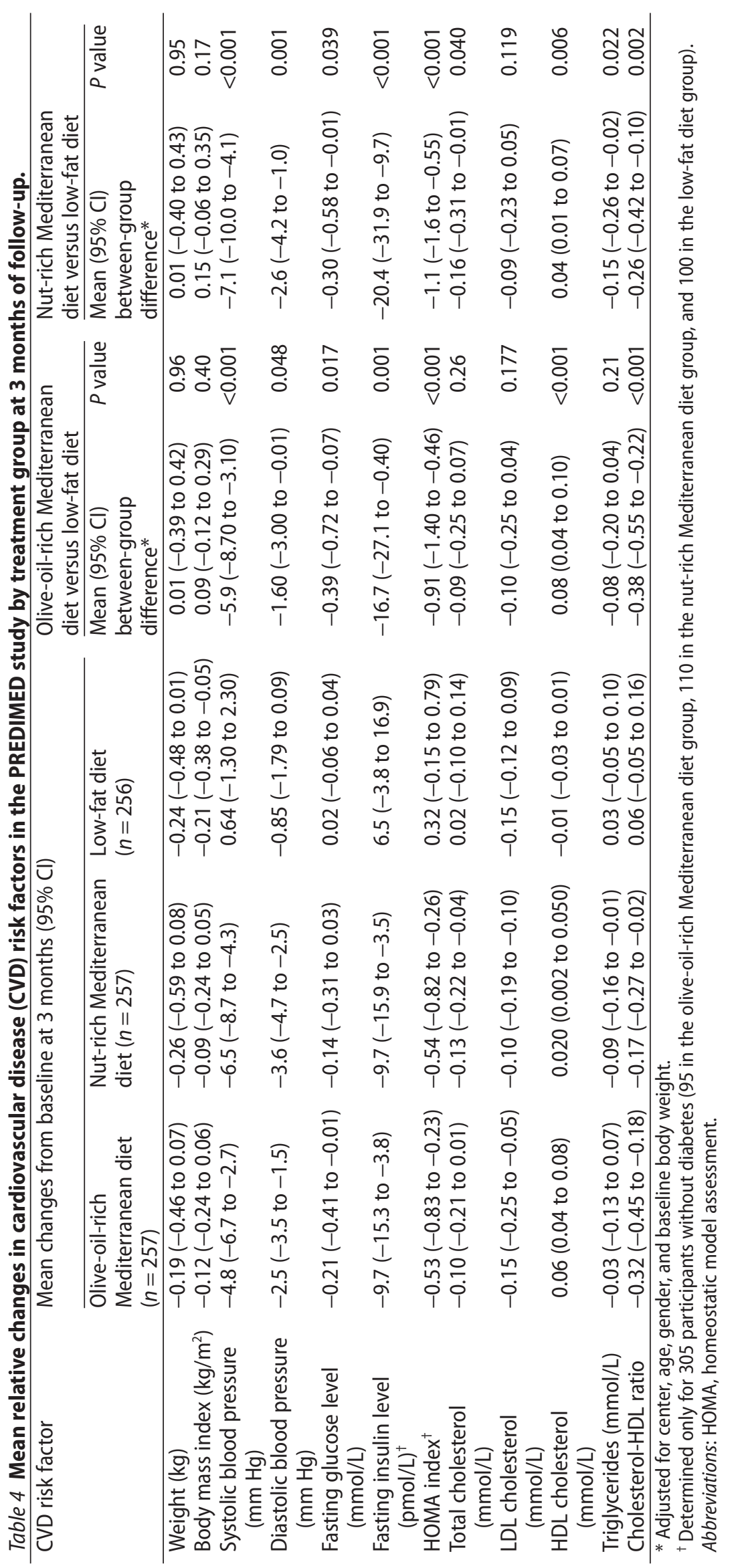




\section{Acknowledgments}

The PREDIMED project is funded by the Spanish government (Instituto de Salud Carlos III, RD06/0045, CIBER CB06/03, PI070240).

Declaration of interest. The authors have no relevant interests to declare.

\section{REFERENCES}

1. Murray CJL, Lopez AD. The Global Burden of Disease: A Comprehensive Assessment of Mortality and Disability from Diseases, Injuries, and Risk Factors in 1990 and Projected to 2020. Boston: Harvard School of Public Health; 1996.

2. Grundy SM, Brewer HB, Cleeman JI, Smith SC, Lenfant C. Definition of metabolic syndrome: report of the National Heart, Lung, and Blood Institute/American Heart Association. Circulation. 2004;109:433-438.

3. Alberti KG, Zimmet P, Shaw J. Metabolic syndrome - a new world-wide definition. A consensus statement from the International Diabetes Federation. Diabet Med. 2006;23:469480.

4. Tong PC, Kong AP, So WY, et al. The usefulness of the International Diabetes Federation and the National Cholesterol Education Program's Adult Treatment Panel III definitions of the metabolic syndrome in predicting coronary heart disease in subjects with type 2 diabetes mellitus. Diabetes Care. 2007;30:1206-1211.

5. Martinez-Gonzalez MA, Sanchez-Villegas A. The emerging role of Mediterranean diets in cardiovascular epidemiology: monounsaturated fats, olive oil, red wine or the whole pattern? Eur J Epidemiol. 2004;19:9-13.

6. Willett WC, Sacks F, Trichopoulou A, et al. Mediterranean diet pyramid: a cultural model for healthy eating. Am J Clin Nutr. 1995;61(Suppl):S1313-S1327.

7. Serra-Majem L, Roman B, Estruch R. Scientific evidence of interventions using the Mediterranean diet: a systematic review. Nutr Rev. 2006;64(Suppl):S27-S47.

8. Trichopoulou A, Costacou T, Bamia C, Trichopoulous D. Adherence to a Mediterranean diet and survival in a Greek population. N Engl J Med. 2003;348:2599-2608.

9. Trichopoulou A, Orfanos P, Norat T, et al. Modified Mediterranean diet and survival: the EPIC-Elderly study. BMJ. 2005;330:991-998.

10. Segui-Gomez $M$, de la Fuente C, Vazquez $Z$, de Irala J, Martinez-Gonzalez MA. Cohort profile: the "Seguimiento Universidad de Navarra" (SUN) study. Int J Epidemiol. 2006; 35:1417-1422.
11. Martínez-González MA, Sánchez-Villegas A, De Irala J, Marti A, Martínez JA. Mediterranean diet and stroke: objectives and design of the SUN project. Nutr Neurosci. 2002;5:65-73.

12. Bes-Rastrollo M, Perez Valdivieso JR, Sanchez-Villegas A, Alonso A, Martinez-Gonzalez MA. Validacion del peso e indice de masa corporal auto-declarados de los participantes de una cohorte de graduados universitarios. Rev Esp Obes. 2005;3:183-189.

13. Alonso A, Beunza JJ, Delgado-Rodriguez M, MartinezGonzalez MA. Validation of self -reported diagnosis of hypertension in a cohort of university graduates in Spain. BMC Public Health. 2005;5:94.

14. Martínez-González MA, López-Fontana C, Varo J, Sánchez-Villegas A, Martínez JA. Validation of the Spanish version of the physical activity questionnaire used in the Nurses' and Health Professionals Follow-up Study. Public Health Nutr. 2005;8:920-927.

15. Martín-Moreno JM, Boyle P, Gorgojo L, et al. Development and validation of a food frequency questionnaire in Spain. Int J Epidemiol. 1993;22:512-519.

16. Vincent S, Gerber M, Bernard MC, et al. The Medi-RIVAGE study (Mediterranean Diet, Cardiovascular Risks and Gene Polymorphisms): rationale, recruitment, design, dietary intervention and baseline characteristics of participants. Public Health Nutr. 2000;3:273-283.

17. Estruch R, Martinez-Gonzalez MA, Corella D, et al. Effects of a Mediterranean-style diet on cardiovascular risk factors. A randomized trial. Ann Intern Med. 2006;145:1-11.

18. Bes-Rastrollo $M$, Sánchez-Villegas $A$, de la Fuente $C$, de Irala J, Martínez JA, Martínez-González MA. Olive oil consumption and weight change: the SUN prospective cohort study. Lipids. 2006;41:249-256.

19. Alonso A, Martínez-González MA. Olive oil consumption and reduced incidence of hypertension: the SUN study. Lipids. 2004;39:1233-1238.

20. Alonso A, Beunza JJ, Bes-Rastrollo M, Pajares RM, Martínez-González MA. Vegetable protein and fiber from cereal are inversely associated with the risk of hypertension in a Spanish cohort. Arch Med Res. 2006;37:778-786.

21. Sánchez-Villegas A, Bes-Rastrollo M, Martínez-González MA, Serra-Majem L. Adherence to a Mediterranean dietary pattern and weight gain in a follow-up study: the SUN cohort. Int J Obes. 2006;30:350-358.

22. Bes-Rastrollo $M$, Sabaté J, Gómez-Gracia $E$, Alonso $A$, Martínez JA, Martínez-González MA. Nut consumption and weight gain in a Mediterranean cohort: the SUN Study. Obesity. 2007;15:107-116.

23. Vincent-Baudry S, Defoort C, Gerber M, et al. The MediRIVAGE study: reduction of cardiovascular disease risk factors after a 3-mo intervention with a Mediterranean-type diet or a low-fat diet. Am J Clin Nutr. 2005;82:964-971. 